\title{
Exact biclustering algorithm for the analysis of large gene expression data sets
}

\author{
Oliver Voggenreiter ${ }^{1 *}$, Stefan Bleuler ${ }^{2}$, Wilhelm Gruissem ${ }^{1}$ \\ From Eighth International Society for Computational Biology (ISCB) Student Council Symposium 2012 \\ Long Beach, CA, USA. 13-14 July 2012
}

\section{Background}

Biclustering of gene expression data is used to discover groups of genes that are co-expressed over a subset of tested conditions. The objective is to maximize the detection of significant biclusters; to do so, most approaches employ a heuristic approximation in order to avoid a nonpolynomial computational complexity.

Previous algorithms have focused on enabling the discovery of biologically relevant results within the scope of single studies, where data size and complexity are limited. New methods and algorithms are required in order to enable applications of biclustering to larger scale data sets that can span multiple experiments and that are potentially far more heterogenous.

\section{Results}

The BiMax [1] algorithm uses a binary representation of the gene expression matrix that has been proven to discover enriched modules of biologically relevant genes in gene expression data. This model of biclustering allows for exact solutions, however, the BiMax algorithm performs best on a restricted size of input data. We can view the biclustering formulation of BiMax as the search for all maximal bicliques in a bipartite graph; where the nodes are genes or experiments and a connection between a gene and an experiment exists if the gene was significantly expressed in that experiment. We propose a new algorithm capable of enumerating all biclusters on such a graph. In order to solve the maximal biclique enumeration problem, we make use of the backtracking Bron-Kerbosch algorithm [2] for maximal clique enumeration. We have developed and successfully tested a new algorithm, the Bipartite Bron-Kerbosch algorithm, which uses similar principles to Bron-Kerbosch but traverses the bicliques on bipartite graphs. This approach enables the algorithm to explore all maximal bicliques without visiting branches of the search tree that contain previously discovered biclusters.

\section{Conclusions}

Our results, see Table 1, conclude that the new algorithm is significantly faster at bicluster exploration than BiMax, demonstrating a factor $n$ improvement in running time

Table 1 BiMax vs. Bipartite Bron-Kerbosch Running Times. Running times of the Bipartite Bron-Kerbosch (BBK) algorithm compared to BiMax on binary matrices derived from $A$. Thaliana gene expression data. Each matrix had a density of around $12 \%$ and the algorithms were given a maximum of 1 hour to complete on the same computer. The number of biclusters in each matrix is listed in the last column.

\begin{tabular}{cccc}
\hline Dimensions & BiMax & $\underline{\text { BBK }}$ & $\underline{\underline{B i c l u s t e r s}}$ \\
\hline $100 \times 100$ & $75 \mathrm{msec}$ & $69 \mathrm{msec}$ & 885 \\
$200 \times 200$ & $340 \mathrm{msec}$ & $168 \mathrm{msec}$ & 4327 \\
$400 \times 400$ & $3 \mathrm{sec}$ & $354 \mathrm{msec}$ & 37583 \\
$800 \times 800$ & $3 \mathrm{~min} 9 \mathrm{sec}$ & $3 \mathrm{sec}$ & 590406 \\
$1000 \times 1000$ & $26 \mathrm{mins} 40 \mathrm{sec}$ & $15 \mathrm{sec}$ & 3103939 \\
$1200 \times 1200$ & - & $1 \mathrm{~min} 41 \mathrm{sec}$ & 16118494 \\
\hline
\end{tabular}

\footnotetext{
* Correspondence: oliverv@ethz.ch

'Department of Biology, ETH Zürich, Zürich, Switzerland

Full list of author information is available at the end of the article
}

(c) 2012 Voggenreiter et al; licensee BioMed Central Ltd. This is an Open Access article distributed under the terms of the Creative 
(where $n$ is proportional to the input data size). For instance, with input data of 800 genes and 800 experiments, BiMax solved for the over 500 thousand biclusters in just over three minutes whereas the Bipartite BronKerbosch algorithm takes approximately 3 seconds.

\section{Author details}

'Department of Biology, ETH Zürich, Zürich, Switzerland. Nebion AG, Zürich, Switzerland

Published: 14 December 2012

\section{References}

1. Prelic A, Bleuler S, Zimmermann P, Wille A, Buhlmann P, Gruissem W, Hennig L, Thiele L, Zitzler E: A systematic comparison and evaluation of biclustering methods for gene expression data. Bioinformatics 2006, 22(9):1122-1129.

2. Bron C, Kerbosch J: Finding All Cliques of an Undirected Graph. Communications of the ACM 1973, 16(9):3.

doi:10.1186/1471-2105-13-S18-A10

Cite this article as: Voggenreiter et al.: Exact biclustering algorithm for the analysis of large gene expression data sets. BMC Bioinformatics 2012 13(Suppl 18):A10.

\section{Submit your next manuscript to BioMed Central} and take full advantage of:

- Convenient online submission

- Thorough peer review

- No space constraints or color figure charges

- Immediate publication on acceptance

- Inclusion in PubMed, CAS, Scopus and Google Scholar

- Research which is freely available for redistribution

Submit your manuscript at www.biomedcentral.com/submit 